\title{
ELECTRONIC MONEY: THE PROBLEM OF DETERMINING THE PLACE IN THE SYSTEM OF OBJECTS OF CIVIL RIGHTS
}

\author{
Ekaterina M. Vavilova \\ Financial University under the Government of the Russian Federation (Financial University), \\ Moscow, Russian Federation
}

\begin{abstract}
Introduction: with the development of the digital economy, the sphere of non-cash payments reaches its peak value. This legal institution is particularly important in connection with the goal set in Russia's strategic documents to improve the quality of non-cash payments and bring them to a new, technologically advanced level. The good legal regulation of certain legal issues in this regard is one of the most urgent tasks of the modern state. In this regard, the author aims to study an important element of the system of non-cash payments -electronic money - and determine its place in the civil rights system. Methods: the methodological framework for this research is a set of methods of scientific knowledge, among which the main ones are the comparative legal method, as well as the methods of systematicity and analysis. Results: the author's well-founded position is based on the analysis of the legislation and opinions of the scientists expressed in the competent scientific community on the issue of recognizing electronic money as an object of civil rights and, accordingly, assigning it to a certain category of objects named in Article 128 of the Civil Code of the Russian Federation. Conclusions: the study proved that the lack of full understanding of the legal nature of electronic money was connected with the unresolved issue of its belonging to the objects of civil rights, in whose connection it substantiated the belonging of electronic money to the rights of obligation to claim to be included in Article 128 of the Civil Code of the Russian Federation as an object of civil rights.
\end{abstract}

Key words: electronic money, civil rights objects, non-cash payments, legal regulation, digital economy.

Citation. Vavilova E.M. Electronic Money: the Problem of Determining the Place in the System of Objects of Civil Rights. Legal Concept, 2020, vol. 19, no. 2, pp. 110-115. (in Russian). DOI: https://doi.org/10.15688/ lc.jvolsu.2020.2.16

\section{ЭЛЕКТРОННЫЕ ДЕНЕЖНЫЕ СРЕДСТВА: ПРОБЛЕМА ОПРЕДЕЛЕНИЯ МЕСТА В СИСТЕМЕ ОБЪЕКТОВ ГРАЖДАНСКИХ ПРАВ}

\author{
Екатерина Михайловна Вавилова \\ Финансовый университет при Правительстве Российской Федерации (Финуниверситет), \\ г. Москва, Российская Федерация
}

Введение: в условиях развития цифровой экономики сфера безналичных расчетов достигает своего пикового значения. Особую важность данный правовой институт приобретает в связи с поставленной в стратегически важных документах России целью повысить качество осуществления безналичных расчетов и вывести их на новый, технологически развитый уровень. Качественное правовое регулирование отдельных правовых вопросов в данной связи является одной из актуальнейших задач современного государства. В связи с этим автором в работе поставлена цель исследования важного элемента системы безналичных расчетов 
- электронных денежных средств и определения их места в системе гражданских прав. Методы: методологическую основу настоящего исследования составляет совокупность методов научного познания, среди которых основное место занимает сравнительно-правовой метод, а также методы системности и анализа. Результаты: обоснованная в работе авторская позиция построена на анализе законодательства и мнений ученых, выраженных в компетентной научной среде по вопросу о признании за электронными денежными средствами статуса объекта гражданских прав и, соответственно, отнесения их к определенной категории объектов, поименованных в ст. 128 Гражданского кодекса Российской Федерации. Выводы: в результате исследования доказано, что отсутствие полноценного понимания правовой природы электронных денежных средств связано с неразрешенностью вопроса о принадлежности их к объектам гражданских прав, в связи с чем обоснована принадлежность электронных денежных средств к числу обязательственных прав требования, подлежащих включению в ст. 128 ГК РФ в качестве объекта гражданских прав.

Ключевые слова: электронные денежные средства, объекты гражданских прав, безналичные расчеты, правовое регулирование, цифровая экономика.

Цитирование. Вавилова Е. М. Электронные денежные средства: проблема определения места в системе объектов гражданских прав // Legal Concept = Правовая парадигма. - 2020. - T. 19, № 2. - C. 110-115. - DOI: https://doi.org/10.15688/lc.jvolsu.2020.2.16

\section{Введение}

Современная мировая экономика претерпевает колоссальные изменения, связанные с вовлеченностью инноваций и технологий во все сферы жизнедеятельности. Уровень экономики выступает ключевым показателем конкурентоспособности стран на международном пространстве, что закреплено в «Стратегии развития информационного общества в Российской Федерации на 2017-2030 годы» [15], утвержденной Указом Президента от 09.05.2017 года. Развитие системы безналичных расчетов в данной связи является основным направлением развития ${ }^{1}[7 ; 8 ; 14]$, а перевод электронных денежных средств (далее - ЭДС) - как наиболее новая и перспективная форма безналичных расчетов, требует особого внимания и нуждается в качественной правовой регламентации. В связи с этим актуальными являются вопросы определения места ЭДС в гражданском и валютном законодательстве. Этим вопросам посвящено настоящее исследование, в результате которого обоснована необходимость определения места ЭДС среди объектов гражданских прав, а именно, в качестве обязательственного права требования.

\section{Проблема определения места электронных денежных средств в гражданском законодательстве}

Вплоть до 2011 г. легальное определение ЭДС отсутствовало в российском законодатель- стве. Затем Федеральным законом № 161-Ф3 «О национальной платежной системе» [17] ЭДС были определены как денежные средства, предварительно предоставленные одним лицом другому (обязанному) лицу для выполнения денежных обязательств первого перед иными лицами.

При этом российское законодательство в качестве денег закрепляет наличные денежные средства в виде банкнот и монет [18] (рубль является законным платежным средством [3]) и денежные средства на банковских счетах и вкладах [16]. Таким образом, ЭДС находятся в «подвешенном» состоянии и не имеют четкой правовой регламентации.

На этот счет в правовой доктрине существует множество позиций, однако единого подхода к пониманию правовой природы ЭДС не выработано.

Для начала следует обратиться к работам Д.А. Гаврина, справедливо отметившего в своих трудах, что признание ЭДС в качестве «денежных средств» является «революционным» положением современного российского законодательства [2, с. 41]. В этой связи автором отмечается крайняя необходимость четкого, структурированного законодательства в рассматриваемой области, которое на сегодняшний день отсутствует.

Разделяясь на несколько «лагерей», ученые-правоведы и экономисты сформировали следующие основные подходы к пониманию правовой природы ЭДС:

1. ЭДС - денежные суррогаты. 
Так, Д.С. Любшина и А.В. Золотарюк рассматривают ЭДС как электронную версию денег [10, с. 146], а О.И. Лаврушин - как суррогаты денег (как и векселя с чеками) [6, с. 9].

Разделяя эту точку зрения, Т.А. Дельцова в своих трудах раскрывает перечень существующих аналогов денежных суррогатов, среди которых выделяет отечественные сервисы (WebMoneyTransfer, Яндекс.Деньги, QIWI) и международные (PayPal, E-Gold и EasyPay) [5, c. 245].

Опровержением таких точек зрения выступает норма Федерального закона от 10.07.2002 № 86-Ф3 «О Центральном банке Российской Федерации», согласно которой на территории Российской Федерации запрещен выпуск денежных суррогатов [18]. Аналогичную позицию выражает и Генеральная прокуратура Российской Федерации на своем официальном сайте [11], а также такие ученые правоведы, как А.В. Шамраева [19, с. 19] и А.И. Савельев [13, с. 249], акцентирующие внимание на том, что законодатель при отнесении расчетов в форме перевода ЭДС к иной форме безналичных расчетов в Гражданском кодексе Российской Федерации (далее ГК РФ) [4] руководствовался уходом «от вопроса о денежных суррогатах и частной эмиссии денег» [19, с. 17].

Кроме того, сторонниками такого подхода не даны четкие, убедительные критерии, позволяющие определить место ЭДС в системе объектов гражданских прав: в качестве вещей (как наличные деньги, документарные ценные бумаги) или в качестве имущественных прав (как безналичные деньги и бездокументарные ценные бумаги).

2. ЭДС - новая форма денег.

Такой точки зрения придерживается профессор В.С. Аксенов, который считает, что ЭДС выступают одной из тех форм, в которую воплотились деньги в результате эволюции $[1$, c. 20$]$. Похожей позиции придерживается и Д.А. Кочергин, определяющий ЭДС в качестве нового средства платежа, которое дает возможность осуществлять потребителям платежные операции без наличия обязательного доступа к депозитным счетам и без участия посредника (эмитента) [9, с. 56].

Примечательно, что выделение ЭДС в качестве самостоятельной формы денег свой- ственно законодательствам многих европейских стран. Например, Центральным банком Европы ЭДС выделяются как отдельная форма денег еще с 2002 г., при этом ведется сепаративный учет их обращения в еврозоне [21]. Помимо этого, в 2000 г. была утверждена директива Европейского парламента и совета № 2000/46/ЕС от 18 сентября 2000 г. «О деятельности в сфере электронных денег и пруденциальном надзоре над институтами, занимающимися этой деятельностью» [20], где нашло свое отражение определение ЭДС, в котором ЭДС приравниваются к денежной стоимости, принимаемой в качестве средства платежа не только эмитентом, но и другими фирмами.

С одной стороны, представители этого направления правы хотя бы по тем основаниям, что непосредственно в статье Федерального закона от 27.06.2011 № 161-Ф3 «О национальной платежной системе» указано, что ЭДС - это денежные средства, которые являются требованиями к оператору ЭДС. С другой стороны, при совокупном изучении существующих норм законодательства, следует вывод, что их правовая природа не определена, и вопрос о принадлежности к денежным средствам является спорным.

Так, ст. 140 ГК РФ «Деньги (валюта)» не содержит упоминания об ЭДС, отражая лишь сведения о наличных и безналичных расчетах на территории Российской Федерации [3]. Аналогичная ситуация складывается при обращении к ст. 128 ГК РФ, в которой определены объекты гражданских прав, среди которых выделяются наличные деньги (как вещь) и безналичные денежные средства (как имущественные права) [3].

\section{Выводы}

Подводя итог, автор приходит к выводу, что российское законодательство идет по пути признания за ЭДС статуса денежных средств. Наряду с этим, очевидна проблема комплексной неполноценности законодательства, при которой не определено место ЭДС в качестве объекта гражданских прав.

Таким образом, с целью обеспечения качественного правового регулирования ЭДС нуждаются в определении места среди объек- 
тов гражданских прав, причем в категории иного имущества, в качестве обязательственного права требования, по следующим основаниям:

1. Как отмечалось выше, Федеральный закон от 27.06.2011 № 161-Ф3 «О национальной платежной системе» определяет ЭДС как требование к оператору ЭДС.

2. При этом ст. 38 названного закона регламентировано, что лица, не являющиеся операторами ЭДС, не могут быть обязанными по ЭДС.

3. Попадая под сферу обязательственного права, ЭДС не относится к вещам, поскольку они не выражены в материальном виде (как, например, наличные деньги). При этом, определяя место ЭДС в числе объектов гражданских прав, их стоит относить к категории иного, «материально невыраженного» имущества, а именно, как обязательственного права требования. В данной связи интересно обратиться к судебной практике, в частности, к Постановлению Девятого арбитражного апелляционного суда от 15.05.2018 № 09АП-16416/2018 по делу № А40-124668/ 2017, где судом отмечается, что действующим гражданским законодательством не закреплено расширительное определение «иного имущества», упомянутого в ст. 128 ГК РФ, а значит, в условиях современной экономической ситуации и уровня развития информационных технологий допустимо максимально широкое его толкование [12].

\section{ПРИМЕЧАНИЕ}

${ }^{1}$ Необходимость развития системы безналичных расчетов и нормативной базы, регулирующей данную сферу, обозначена в стратегических документах Банка России.

\section{СПИСОК ЛИТЕРАТУРЫ}

1. Аксенов, В. С. Электронные деньги: универсальное средство для экономики / В. С. Аксенов ; под ред. Н. Н. Калининой. - М. : МПА-Пресс, 2009. - С. 20-26.

2. Гаврин, Д. А. Электронные денежные средства: проблемы правового регулирования / Д. А. Гаврин // Банковское право. - 2018. - № 5. - С. 41-47.

3. Гражданский кодекс Российской Федерации (часть первая) от 30.11.1994 № 51-Ф3 // Собра- ние законодательства РФ. - 1994. - 5 дек. (№ 32). Ст. 3301.

4. Гражданский кодекс Российской Федерации (часть вторая) от 26.01.1996 № 14-Ф3 // Собрание законодательства РФ. - 1996. - 29 янв. (№ 5). Ст. 410.

5. Дельцова, Т. А. Многообразие денежных суррогатов в природе или в чем заключается свобода выбора? / Т. А. Дельцова // Вестник Пермского национального исследовательского политехнического университета. - 2017. - С. 241-250.

6. Деньги, кредит, банки : учебник / под ред. О. И. Лаврушина. - 7-е изд., стер. - М. : КНОРУС, 2008.-357 c.

7. Документ Банка России от 2019 г. «Основные направления развития финансового рынка Российской Федерации на период 2019-2021 годов». Электрон. текстовые дан. - Режим доступа: https:// www.cbr.ru/Content/Document/File/71220/main directions.pdf (дата обращения: 29.03.2020). - Загл. с экрана.

8. Документ Банка России от 2018 г. «Основные направления развития финансовых технологий на период 2018-2020 годов». - Электрон. текстовые дан. - Режим доступа: https://www.cbr.ru/ StaticHtml/ File/41186/ON_FinTex_2017.pdf(дата обращения: 29.03.2020). - Загл. с экрана.

9. Кочергин, Д. А. Электронные деньги: Теория и анализ моделей эмиссии / Д. А. Кочергин. СПб. : Изд-во СПГУ, 2006. - С. 50-67.

10. Любшина, Д. С. Криптовалюта как инновационный инструмент мировой торговли / Д. С. Любшина, А. В. Золотарюк // Интерактивная наука. 2016. -№ 10. - С. 145-146.

11. Официальный сайт Генеральной прокуратуры Российской Федерации. - Электрон. текстовые дан. - Режим доступа: http://www.genproc. gov.ru/smi/news/genproc/news-86432/ (дата обращения: 29.03.2020). - Загл. с экрана.

12. Постановление Девятого арбитражного апелляционного суда от 15.05.2018 № 09АП-16416/ 2018 по делу № А40-124668/2017. - Доступ из справ.правовой системы «КонсультантПлюс».

13. Савельев, А. И. Электронная коммерция в России и за рубежом: правовое регулирование / А. И. Савельев. -2-е изд. - М. : Статуг, 2016. -640 с.

14. Стратегия повышения финансовой доступности в Российской Федерации на период 20182020 годов (одобрено Советом директоров Банка России 26.03.2018). - Электрон. текстовые дан. - Режим доступа: https:/www.cbr.ru/Content/Document/ File/44104/str_30032018.pdf (дата обращения: 29.03.2020). - Загл. с экрана.

15. Указ Президента РФ от 09.05.2017 № 203 «О Стратегии развития информационного общества в Российской Федерации на 2017-2030 годы» // Со- 
брание законодательства РФ. - 2017. - 15 мая (№ 20). - Ст. 2901.

16. Федеральный закон от 10.12.2003 № 173-Ф3 «О валютном регулировании и валютном контроле» // Собрание законодательства РФ. - 2003. 15 дек. (№ 50). - Ст. 4859.

17. Федеральный закон от 27.06.2011 № 161Ф3 «О национальной платежной системе» // Собрание законодательства РФ. - 2011. - 4 июля (№ 27). - Ст. 3872.

18. Федеральный закон от 10.07.2002 № 86-Ф3 «О Центральном банке Российской Федерации» // Собрание законодательства РФ. - 2002. 15 июля (№ 28). - Ст. 2790.

19. Шамраев, А. В. Законодательство о национальной платежной системе и его влияние на развитие платежных инноваций / А. В. Шамраев // Банковское право. - 2011. - № 5. - С. 13-21.

20. Directive of the European Parliament and of the Council 2000/46/EC of 18.09.2000 "On the taking up, pursuit of and prudential supervision of the business of electronic money institutions". Electronic text data. - Mode of access: https://eurlex.europa.eu/legal-content/EN/ALL/? uri=CELEX\% 3A32000L0046 (date of access: 29.03.2020). - Title from screen.

21. European Central Bank. Statistics: Money, banking and financial markets: Monetary statistics: Electronic Money. - Electronic text data. - Mode of access: http://www.ecb.int/stats/money/ aggregates/ emon $/ \mathrm{html} /$ index.en.html\#data (date of access: 29.03.2020). - Title from screen.

\section{REFERENCES}

1. Aksenov V.S., Kalinina N.N., ed. Elektronnyye dengi: universalnoye sredstvo dlya ekonomiki [Electronic Money: A Universal Tool for the Economy]. Moscow, MPA-Press, 2009, no. 1-2, pp. 20-26.

2. Gavrin D.A. Elektronnyye denezhnyye sredstva: problemy pravovogo regulirovaniya [Electronic Money: Problems of Legal Regulation]. Bankovskoe pravo [Banking Law], 2018, no. 5, pp. 41-47.

3. Grazhdanskiy kodeks Rossiyskoy Federatsii (chast pervaya) ot 30.11.1994 № 51-FZ [“Civil Code of the Russian Federation (Part One)" of November 30, 1994 No. 51-FL]. Sobraniye zakonodatelstva RF [Collection of Legislation of the Russian Federation], 1994, Dec. 5 (no. 32), art. 3301.

4. Grazhdanskiy kodeks Rossiyskoy Federatsii (chast vtoraya) ot 26.01.1996 № 14-FZ [“Civil Code of the Russian Federation (Part Two)" of January 26, 1996 No. 14-FL]. Sobraniye zakonodatelstva $R F$ [Collection of Legislation of the Russian Federation], 1996, Jan. 29 (no. 5), art. 410.
5. Deltsova T.A. Mnogoobraziye denezhnykh surrogatov v prirode ili v chem zaklyuchayetsya svoboda vybora? [The Variety of Money Substitutes in Nature or What is the Freedom of Choice?]. Vestnik Permskogo natsionalnogo issledovatelskogo politekhnicheskogo universiteta [Bulletin of Perm National Research Polytechnic University], 2017, pp. 241-250.

6. Lavrushin O.I., ed. Dengi, kredit, banki: uchebnik [Money, Credit, Banks: Textbook]. 7-e izd., ster. Moscow, KNORUS Publ., 2008. 357 p.

7. Dokument Banka Rossii ot $2019 \mathrm{~g}$. "Osnovnyye napravleniya razvitiya finansovogo rynka Rossiyskoy Federatsii na period 20192021 godov» [Bank of Russia Document of 2019, "The Main Directions of Development of the Financial Market of the Russian Federation for the Period 20192021 Years"]. URL: https://www.cbr.ru/Content/ Document/File/71220/main_directions.pdf(accessed: 29 March 2020).

8. Dokument Banka Rossii ot $2018 \mathrm{~g}$. "Osnovnyye napravleniya razvitiya finansovykh tekhnologiy na period 2018-2020 godov» [Bank of Russia Document of 2018, "The Main Directions of Development of Financial Technologies for the Period 2018-2020 Years"]. URL: https://www.cbr.ru/ StaticHtml/File/41186/ON_FinTex_2017.pdf(accessed: 29 March 2020).

9. Kochergin D.A. Elektronnyye dengi: Teoriya $i$ analiz modeley emissii [Electronic Money: Theory and Analysis of Emission Models]. Saint Petersburg, Saint Petersburg State University, 2006, pp. 50-67.

10. Liubshina D.S., Zolotaryuk A.V. Kriptovalyuta kak innovatsionnyy instrument mirovoy torgovli [Cryptocurrency as an Innovative Tool of World Trade]. Interaktivnaya nauka [Interactive Science], 2016, no. 10, pp. 145-146.

11. Ofitsialnyy sayt Generalnoy prokuratury Rossiyskoy Federatsii [The Official Website of the State Prosecutor's Office of the Russian Federation]. URL: http://www.genproc.gov.ru/smi/news/genproc/ news-86432/ (accessed: 29 March 2020).

12. Postanovleniye Devyatogo arbitrazhnogo apellyatsionnogo suda ot 15.05.2018 № 09AP-16416/ 2018 po delu № A40-124668/2017 [The Decision of the Ninth Arbitration Court of Appeal Dated 05/15/2018 No. 09AP-16416/2018 in the Case No. A40-124668/ 2017]. Access from Reference Legal Sistem "KonsultantPlyus".

13. Savelyev A.I. Elektronnaya kommertsiya v Rossii i za rubezhom: pravovoye regulirovaniye [E-Commerce in Russia and Abroad: Legal Regulation. $2^{\text {nd }}$ ed.]. 2-e izd. Moscow, Statut Publ., 2016. 640 p.

14. Strategiya povysheniya finansovoy dostupnosti $v$ Rossiyskoy Federatsii na period 20182020 godov (odobreno Sovetom direktorov Banka 
E.M. Вавилова. Электронные денежные средства: проблема определения места в системе объектов

Rossii 26.03.2018) ["Strategy for Increasing Financial Affordability in the Russian Federation for the Period 2018-2020 Years" (Approved by the Board of Directors of the Bank of Russia on 26 March 2018)]. URL: https:// www.cbr.ru/Content/Document/File/44104/str 30032018.pdf(accessed: 29 March 2020).

15. Ukaz Prezidenta RF ot 09.05.2017 № 203 «O Strategii razvitiya informatsionnogo obshchestva $\mathrm{V}$ Rossiyskoy Federatsii na 2017-2030 gody»» [Decree of the President of the Russian Federation of 05.09.2017 No. 203 "On the strategy for the Development of the Information Society in the Russian Federation for 2017-2030 Years"]. Sobraniye zakonodatelstva $R F$ [Collection of Legislation of the Russian Federation], 2017, May 15 (no. 20), art. 2901.

16. Federalnyy zakon ot 10.12.2003 № 173-FZ «O valyutnom regulirovanii i valyutnom kontrole» [Federal Law of 10 December 2003 No. 173-FL “On Currency Regulation and Currency Control"]. Sobraniye zakonodatelstva $R F$ [Collection of Legislation of the Russian Federation], 2003, Dec. 15 (no. 50), art. 4859.

17. Federalnyy zakon ot 27.06.2011 № 161-FZ «O natsionalnoy platezhnoy sisteme» [Federal Law of 27 June 2011 No. 161-FL "On the National Payment System"]. Sobraniye zakonodatelstva RF [Collection of Legislation of the Russian Federation], 2011, Jul. 4 (no. 27), art. 3872.

18. Federalnyy zakon ot 10.07.2002 № 86-FZ «O Tsentralnom banke Rossiyskoy Federatsii» [Federal Law Dated 10 July 2002 No. 86-FL “On the Central Bank of the Russian Federation"]. Sobraniye zakonodatelstva RF [Collection of Legislation of the Russian Federation], 2002, Jul. 15 (no. 28), art. 2790.

19. Shamrayev A.V. Zakonodatelstvo o natsionalnoy platezhnoy sisteme i ego vliyaniye na razvitiye platezhnykh innovatsiy [The Legislation on the National Payment System and its Impact on the Development of Payment Innovations]. Bankovskoye pravo [Banking Law], 2011, no. 5, pp. 13-21.

20. Directive of the European Parliament and of the Council 2000/46/EC of 18.09.2000 "On the Taking up, Pursuit of and Prudential Supervision of the Business of Electronic Money Institutions». URL: https:/eur-lex.europa.eu/legal-content/EN/ALL/? uri=CELEX\%3A32000L0046 (accessed: 29 March 2020).

21. European Central Bank. Statistics: Money, Banking and Financial Markets: Monetary Statistics: Electronic Money. URL: http://www.ecb.int/stats/ money/ aggregates/emon /html/index.en.html\#data (accessed: 29 March 2020).

\section{Information About the Author}

Ekaterina M. Vavilova, Postgraduate Student, Faculty of Law, Department of the Legal Regulation of Economic Activity, Financial University under the Government of the Russian Federation (Financial University), Prosp. Leningradskiy, 49, 125167 Moscow, Russian Federation, academy@fa.ru, Katyashh@bk.ru, https://orcid.org/0000-0003-2838-5208

\section{Информация об авторе}

Екатерина Михайловна Вавилова, аспирант 2-го курса Юридического факультета, Департамент правового регулирования экономической деятельности, Финансовый университет при Правительстве Российской Федерации (Финуниверситет), просп. Ленинградский, 49, 125167 г. Москва, Российская Федерация, academy@fa.ru, Katyashh@bk.ru, https://orcid.org/0000-0003-2838-5208 